\title{
Deoxynivalenol Content in Italian Organic Durum Wheat: Results of a Six-year Survey
}

\author{
M. Camerini ${ }^{1 *}$, T. Amoriello ${ }^{2}$, G. Aureli ${ }^{1}$, A. Belocchi ${ }^{1}$, M. Fornara ${ }^{1}$, \\ S. MELLONI ${ }^{1}$ and F. QUARANTA ${ }^{1}$ \\ ${ }^{1}$ Consiglio per la ricerca e la sperimentazione in agricoltura - Unità di Ricerca per la Valorizzazione \\ Qualitativa dei Cereali (CRA-QCE), via Cassia 176, 00191 Roma, Italy \\ ${ }^{2}$ Consiglio per la ricerca e la sperimentazione in agricoltura - Centro di Ricerca per gli Alimenti \\ e la Nutrizione (CRA-NUT), via Ardeatina 546, 00178 Roma, Italy
}

(Received 23 December 2014; Accepted 20 May 2015;

Communicated by X.F. Zhang)

\begin{abstract}
Deoxynivalenol (DON) contamination was investigated of Italian durum wheat from organic agriculture. A number of 661 samples from 13 genotypes were collected within the national organic durum wheat network variety trials during the six-year period between 2007-2012 in five different growing areas across Italy (Northern Italy, Marches, Central Apennines, West-Central Italy, Apulia). Mean temperatures and total rainfalls in April, May and June were collected nearby the study sites. Average DON contamination value along the whole study period was $67 \mu \mathrm{g} / \mathrm{kg}$, and DON was detected only in $36 \%$ of the samples. Noteworthy, $95 \%$ of the analyzed grain revealed a DON contamination lower than $334 \mu \mathrm{g} /$ $\mathrm{kg}$. Maximum allowed DON level for unprocessed durum wheat set by European Union $(1750 \mu \mathrm{g} / \mathrm{kg})$ was exceeded only in four samples $(0.6 \%)$. The highest mean DON values were detected in Northern Italy $(175 \mu \mathrm{g} / \mathrm{kg})$ and Marches $(131 \mu \mathrm{g} / \mathrm{kg})$. The same was for the percentage of positive samples ( $80 \%$ and $58 \%$, respectively). Lower mean values and percentages of contaminated samples were found in West-Central Italy $(22 \mu \mathrm{g} / \mathrm{kg}$ and $29 \%$, respectively), Apennines ( $3 \mu \mathrm{g} / \mathrm{kg}$ and $8 \%$, respectively) and Apulia $(2 \mu \mathrm{g} / \mathrm{kg}$ and $7 \%$, respectively). Statistical analysis (Generalized Linear Model, GLZ) was carried out to highlight the effect of factors like cultivation year, growing area and genotype. It revealed a huge effect of year, growing areas and their interaction, while the effect of genotype resulted significantly but quite less than the other main factors. The effect of the year could be explained by climatic data, which suggested an influence of rainfall and temperature at heading on both DON concentration values and percentage of contaminated samples. Results of this study put in evidence a low DON contamination in Italian organic durum wheat.
\end{abstract}

Keywords: durum wheat, organic agriculture, Deoxynivalenol, survey

\section{Introduction}

During the last decade, attention of consumers for organic food increased, since, mainly due to growing ecological awareness, they are perceived healthier and safer than those produced conventionally (Rembiałkowska 2007). According to a survey (European Un-

*Corresponding author; E-mail: massimiliano.camerini@yahoo.it 
ion), at the end of 2011 in European Union 9.614 million hectares were managed organically (accounting for $5.6 \%$ of the total cultivated area), of which 1.405 million hectares were cultivated with cereals (European Commission 2013). In Italy, at the end of 2013 organically cultivated area amounted to 1.317 million hectares; cereals represented $15 \%$ of the total organic surface ( 0.191 million hectares), and durum wheat was largely the most diffused organic cereal, given that it was grown on 0.074 million hectares (SINAB 2014). As the use of synthetic compounds is not permitted to control pathogens, some claims were made about a greater incidence of plant diseases on organically managed crops compared to conventional ones; as a result, food and feed from organic agriculture may be more exposed than those produced conventionally to mycotoxins contamination (Malmauret et al. 2002). Other studies indicated lower mycotoxins levels in organic than in conventional cereals (Błajet-Kosicka et al. 2014; Bernhoft et al. 2010; Edwards 2009a), while no significant differences emerged from other works (Champeil et al. 2004). Among the cereal fungal pathogens, some species of the genus Fusarium are the causal agents of Fusarium Head Blight (FHB), a serious wheat disease reducing grain yield. In Italy, the predominant FHB causal agents are F. graminearum Schwabe (Teleomorph Gibberella zeae Schw. Petch) and F. culmorum (W.G. Smith) Sacc. (Bottalico and Perrone 2002). Such species are major producers of Deoxynivalenol (DON) a mycotoxin which causes reduced feed intake, reduced weight gain and vomiting in farm animals (Anonymous 2004); high concentrations of DON have also adverse effect on humans (Anonymous 1999). European Commission regulation established maximum levels for DON contamination of food and feed (European Commission 2006a). The Maximum Allowed Level (MAL) in unprocessed durum wheat amounts to $1750 \mu \mathrm{g} / \mathrm{kg}$. The aims of this work were: 1) to assess both DON contamination rate and incidence of organically produced durum wheat; 2) to analyze the effect of factors like growing year, cultivation area and genotype on DON concentration. For this purpose, DON contamination was determined in organically produced durum wheat grain collected in several locations across Italy during the 2007-2012 six-year period.

\section{Materials and Methods}

During the 2007-2012 six-year period, 661 mature durum wheat grain samples were collected within the national organic durum wheat network trials, carried out for the evaluation of the overall performance of durum cultivars under organic management. A total of 10 locations (Fig. S1*) were included in this study (seven to ten every year). Locations were grouped in five macroareas (Northern Italy, Marches, Central Apennines, West-Central Italy and Apulia), referred to five different climatic and geographical areas. A number of 13 cultivars characterized by different heading dates with different cycle length (Ciccio, Claudio, Creso, Duilio, San Carlo, Simeto, Colosseo, Meridiano, Svevo, Dylan, Normanno, Saragolla, Vinci), were evaluated every year. In each location, trials were carried out according to a randomized complete block experimental design (RCBD) with three

*Further details about the Electronic Supplementary Material (ESM) can be found at the end of the article. 
replications $\left(10 \mathrm{~m}^{2}\right.$ plots $)$. Average temperature and total rainfall in April, May and June were collected from weather stations placed nearby the experimental sites. Heading date (expressed as days after April $1^{\text {st }}$ ) was determined for each plot following field survey. Heading date was the day on which $50 \%$ of the heads of the plot were completely emerged. After harvesting, grain was air-cleaned. Subsequently, grain from the three replications was bulked, and a representative subsample (European Commission 2006b) was milled, using a Cyclotec-PBI experimental mill (mesh size: $0.5 \mathrm{~mm}$ ). The bulked sample derived by three replicated trials placed randomly within the growing area was considered more representative of the field environment. DON content was determined using an EnzymeLinked Immunosorbent Assay (kit Ridascreen ${ }^{\circledR}$ DON, R-Biopharm) and the automatic system BRIO (SEAC). The Limit of Detection (LOD) of the method was $18.5 \mu \mathrm{g} / \mathrm{kg}$ and the recovery of DON in wheat in spike/recovery assay was from 85 to $110 \%$. The range of recovery declared in the method was between $85 \%$ and $110 \%$. A value of recovery derived from mathematical calculation and exceeding $100 \%$ is in compliance with the Commission Regulation (EC) No. 401/2006 (Annex II). Concentration values were expressed as the mean of duplicated analyses $(\mathrm{CV} \leq 10 \%)$. The amount of samples exceeding the maximum allowed level was assessed taking in account the expanded measurement of uncertainty of data close to the value limit. The uncertainty percentage was as twice the relative standard deviation calculated following the Horwitz function for ELISA methods of analysis for DON contamination in wheat and wheat derived products (Brera 2011). Descriptive statistics of DON were calculated, including mean, standard deviation (SD), minimum concentration (Min), maximum concentration (Max), median (Q2), 75 ${ }^{\text {th }}$ percentile (Q3), and $95^{\text {th }}$ percentile (P95). In order to statistically analyze the data, samples with a DON contamination below LOD were equalized to 0 (Tittlemier et al. 2013). The Generalized Linear Model (GLZ) was applied to assess the influence of three factors (genotype, growing year and cultivation area) and all their two-way interactions on DON contamination. Rare events, such as the occurrence of specific diseases, can be modelled using a Poisson distribution, characterized by the independence of the occurrence, so that one occurrence neither diminishes nor increases the chance of another. This distribution is highly asymmetrical (Fig. S2): when the occurrence of some events is small, the probability will lie near the zero; when the number of incidences becomes commoner, the centre of the distribution moves toward the right. The hump of the Poisson curve represents the likeliest actual occurrence. Therefore, we applied for the response variable DON a Poisson distribution and the logarithm of its expected value E(Y) could be modelled by a linear combination of unknown parameters. Poisson regression models were GLZ with the logarithm as the canonical link function and the Poisson distribution function. The statistical model was:

$$
\log (\mathrm{DON})=\beta_{0}+\tau_{\mathrm{i}}+\delta_{1}+\zeta_{\mathrm{k}}+\tau_{\mathrm{i}} \cdot \delta_{1}+\tau_{\mathrm{i}} \cdot \zeta_{\mathrm{k}}+\delta_{\mathrm{l}} \cdot \zeta_{\mathrm{k}}+\varepsilon_{\mathrm{ilk}}
$$

where

$\beta_{0}=$ mean effect common to all observations;

$\tau_{\mathrm{i}}=$ cultivar $(\mathrm{CV})$ 
i $=1, \ldots, 13$ (Ciccio, Claudio, Colosseo, Creso, Duilio, Dylan, Meridiano, Normanno, San Carlo, Saragolla, Simeto, Svevo, Vinci);

$\delta_{1}=$ year;

$1=1, \ldots, 6(1=2007,2=2008,3=2009,4=2010,5=2011,6=2012)$;

$\zeta_{\mathrm{k}}=$ area;

$\mathrm{k}=1, \ldots, 5$ (Northern Italy, Marches, Central Apennines, West-Central Italy, Apulia);

$\varepsilon=$ error term.

The goodness of fit of GLZ model could be based on the deviance statistic, approximated by a chi-square distribution. We used the log-likelihood value to measure the goodness of fit of the regression models. Statistical analyses were performed using Statistica version 7.1 (StatSoft Italia srl).

\section{Results}

DON was detected in 238 out to 661 samples (36\%); overall, low DON levels were recorded, with an average value of $67 \mu \mathrm{g} / \mathrm{kg}$ and mean of positive samples of $184 \mu \mathrm{g} / \mathrm{kg}$ (Table S1). Even taking into account the expanded measurement of uncertainty (see Materials and Methods), only four samples $(0.6 \%)$ exceeded the value of $1750 \mu \mathrm{g} / \mathrm{kg}$. It is worth to highlight how $95 \%$ of the samples revealed a DON level lower than $334 \mu \mathrm{g} / \mathrm{kg}$. The area with the highest overall mean value was Northern Italy $(175 \mu \mathrm{g} / \mathrm{kg}$, mean of positive samples $218 \mu \mathrm{g} / \mathrm{kg}$ ), while values lower than LOD emerged in Central Apennines and Apulia (Table S1). Huge differences emerged between the percentage of contaminated samples in the study areas, as well as the contamination ranges: in Northern Italy, $80 \%$ of the samples where characterized by detectable DON concentration levels ( $\geq$ LOD), and the overall values ranged from $<\mathrm{LOD}$ to $2610 \mu \mathrm{g} / \mathrm{kg}$; in Marches percentage of positive samples was $58 \%$ and the contamination ranged from $<\mathrm{LOD}$ to $2385 \mu \mathrm{g} / \mathrm{kg}$. A lower number of positive samples emerged in West-Central Italy (29\%), Central Apennines (9\%) and Apulia (7\%). Parallel, ranges of contamination in the latter three areas were narrower than in Northern Italy and Marches $(<\mathrm{LOD}-423 \mu \mathrm{g} / \mathrm{kg}$ in West-Central Italy, $<\mathrm{LOD}-88 \mu \mathrm{g} / \mathrm{kg}$ in Central Apennines, $<\mathrm{LOD}-71 \mu \mathrm{g} / \mathrm{kg}$ in Apulia). Means of positive samples confirmed low contamination levels revealed by overall means. Regarding growing year (Table S1), higher mean DON contaminations were recorded in 2009 and 2008 $(163 \mu \mathrm{g} / \mathrm{kg}$ and $112 \mu \mathrm{g} / \mathrm{kg}$, respectively, mean of positive samples $394 \mu \mathrm{g} / \mathrm{kg}$ and $314 \mu \mathrm{g} /$ $\mathrm{kg}$ ), while overall average levels detected in the remaining years never exceeded $50 \mu \mathrm{g} /$ $\mathrm{kg}$ and the means of positive samples resulted quite below $100 \mu \mathrm{g} / \mathrm{kg}$, with the exception of $2011(151 \mu \mathrm{g} / \mathrm{kg})$. Lower differences emerged in terms of DON incidence, whose values ranged between 30\% (2012) and 42\% (2011). Contaminations of concern were detected in 2008 in Northern Italy (100\% of positive samples, mean DON contamination $715 \mu \mathrm{g} / \mathrm{kg}$, highest detected value $2610 \mu \mathrm{g} / \mathrm{kg}$ ) and 2009 in Marches (96\% of positive samples, mean DON contamination $558 \mu \mathrm{g} / \mathrm{kg}$, mean of positive samples $580 \mu \mathrm{g} / \mathrm{kg}$, highest detected value $2385 \mu \mathrm{g} / \mathrm{kg}$ ). On the contrary, it is worth to highlight how no 
samples were positive for DON in Apulia in 2007 and 2009, and Central Apennines in 2008 and 2009. The high variability observed among different areas and years was also confirmed by GLZ regression (Table S2), which showed a highly significant influence of cultivation area $\left(\chi^{2}=2282, p<0.0001\right)$, growing year $\left(\chi^{2}=2135, p<0.0001\right)$ and their interaction $\left(\chi^{2}=2269, \mathrm{p}<0.0001\right)$ on DON occurrence. Genotype, although statistically significant $\left(\chi^{2}=37, \mathrm{p}<0.0001\right)$, appeared less important than the other main factors. It is confirmed by the low variability emerged between DON occurrence in the examined cultivars (Table S3).

\section{Discussion}

Several papers were published, concerning mycotoxins contamination in unprocessed organic cereals (Edwards 2009a, 2009b, 2009c; Bernhoft et al. 2010), but quite a few of them were about durum wheat (Quaranta et al. 2010). This work gives a clear description of the extent of DON contamination in Italian organic durum, exploring at the same time the effect of important involved factors. Such result was achieved collecting in the main Italian durum wheat growing areas a particularly huge number of samples, along a large time span. Few data are reported in literature regarding DON contamination in organic durum wheat, while more studies are available about conventional durum. Regarding conventional durum wheat, higher levels of incidence and contamination $(12,800 \mu \mathrm{g} / \mathrm{kg}$ to $30,500 \mu \mathrm{g} / \mathrm{kg}$ ) were detected in samples from Tunisia in 2007 (Bensassi et al. 2010). Cendoya et al. (2014) reported a $<50 \mu \mathrm{g} / \mathrm{kg}$ to $15,141 \mu \mathrm{g} / \mathrm{kg}$ DON contamination in durum wheat harvested in Argentina in 2011. Mean concentrations of 25 to $1600 \mu \mathrm{g} / \mathrm{kg}$ and values ranging from $<50$ to $4700 \mu \mathrm{g} / \mathrm{kg}$ were found in conventional durum wheat grain harvested in Canada in 2010 (Tittlemier et al. 2013). Regarding more directly durum wheat in organic farming, Fagnano et al. (2012) reported low DON levels in organic durum wheat following comparisons between organic and conventional management trials in Southern Italy, while Quaranta et al. (2010) found that organic durum wheat was significantly less DON contaminated than conventional one in variety trials in Southern and Central Italy, with values ranging from $<18.5 \mu \mathrm{g} \mathrm{kg}-1$ to $1894 \mu \mathrm{g} / \mathrm{kg}$. Our results suggest a substantial safety of Italian organic durum wheat in terms of DON contamination. Many authors reported about the influence of environmental factors on DON levels in wheat, highlighting how rainfall and warm temperatures at anthesis resulted in an increase of DON presence in wheat (Hooker et al. 2002; Clear et al. 2005). Šlikova et al. (2008) found common wheat from Slovakia to be more DON contaminated in years characterized by heavy rains in June. Huge rainfalls at inoculation time were positively correlated with DON content in grains from spray inoculated wheat plants (Mesterházy 2002). Durum wheat grain from variety trials in Argentina were more heavily DON contaminated when huge rainfalls during heading periods occurred (Lori et al. 2003). Climatic data (Table S4) pointed out that Northern Italy and Marches, the areas showing both the highest percentage of positive samples and the highest mean DON levels, are characterized by more intense rainfall in April and May, the months in which plant heading occurred (Table S5). In the remaining areas, drier conditions and temperature not warm enough at 
heading may be responsible for both lower incidence and mean DON levels. Huge precipitation was recorded in Northern Italy in 2008 in April and May; in particular, $80 \%$ of the total rainfall in May occurred in the second decade (Table S6), when wheat plants were in the heading stage or shortly after such phase. Moreover, such huge decadal rainfall was coupled with higher average temperature. As a result, DON values of concern were detected. In the same year, intense rainfall occurred in April in Marches but, despite $77 \%$ of the samples resulted positive, average value was $81 \mu \mathrm{g} / \mathrm{kg}$ and the highest detected level was $340 \mu \mathrm{g} / \mathrm{kg}$. A possible explanation is that some $70 \%$ of the rainfall in April occurred in the first decade of the month (Table S6), when plants were far from heading. In addition, the first decade of May was very dry (total decadal rainfall $2 \mathrm{~mm}$ ). Taking into account that DON was reported to be weather responsive in the period between 4 to 7 days prior to and 7 to 10 days after heading (Hooker et al. 2002), it is possible to hypothesize that, despite the huge total rainfall in April, environmental condition at heading was not favorable for FHB development in 2008 in Marches. Within-month precipitation distribution revealed to be as important as total one in causing DON contamination levels also in 2009 in Marches, when high DON values were detected. Indeed, almost $60 \%$ of April total rain fell in the last decade, when the most of the heading dates occurred. Further, in 2009 average temperature in May was particularly high $\left(19.4^{\circ} \mathrm{C}\right)$, mainly in the second and third decades. Thus, it is possible to hypothesize that such thermal regime made environmental condition even more suitable for disease development. As reported in the results section, genotype revealed to be less statistically important than the others involved factors. In bread wheat, a strong influence of cultivar on field DON contamination was reported (Schaafsma et al. 2001). Blandino et al. (2012) found that a significant DON reduction may be achieved through an integrated strategy based on the use of moderately resistant cultivars and appropriate agronomic tools. Strong effectiveness of genotypic effect on DON contamination of bread wheat also was reported by Tóth et al. (2008) and Tamburic-Ilincic (2012). On the contrary, few sources of resistance were identified in durum and, in general, in tetraploid wheats (Fedak et al. 2007). It follows that no resistant durum varieties were selected so far (Buerstmayr et al. 2009; Bentivenga et al. 2011). In conclusion, results of this study highlighted a substantial safety of Italian durum wheat from organic agriculture in terms of DON contamination, given that only four out of 661 analysed samples exceeded the maximum allowed DON level, and that $95 \%$ of them revealed DON levels lower than $334 \mu \mathrm{g} / \mathrm{kg}$. Such safety is mainly the result of a favorable climatic condition at heading, in terms of average temperature and, most of all, both total rainfall and rainfall distribution. Such results are in agreement with those of other studies on mycotoxins in organic cereals. Particularly, very low DON values were found throughout the whole study period in grain from Southern Italy, Central Apennines and West-Central Italy. Higher values were recorded in Northern Italy and Marches, only when rainy conditions at heading occurred. Further studies on samples from farm fields are needed in order to confirm both DON levels and distribution in commercial organic durum wheat. 


\section{Acknowledgements}

The authors would like to acknowledge Dr. M. Perenzin, Dr. C. Piazza, Dr. G. Mazzieri, Dr. A. Petrini, Dr. P. Bottazzi, Dr. G. Tullo, Dr. V. Galante, Dr. P. Codianni and Prof. L. Tedone for their helpful, excellent collaboration in managing the field trials. This research was performed within the PNSB project, funded by the Italian Ministry of Agricultural, Food and Forestry Policies (MIPAAF, Rome, Italy).

\section{References}

Anonymous 1999. Opinion of the Scientific Committee on Food on Fusarium toxins. Part 1: Deoxynivalenol. European Commission. Brussels, Belgium.

Anonomous 2004. Opinion of the Scientific Panel on the Contaminants in the Food Chain on a request from the Commission related to Deoxynivalenol (DON) as undesirable substance in animal feed. EFSA J. 73:1-41.

Bensassi, F., Zaied, C., Abid, S., Hajlaoui, M.R., Bacha, H. 2010. Occurrence of Deoxynivalenol in durum wheat in Tunisia Food Control 21:281-285.

Bentivenga, G., Ammar, K., Camerini, M., Fornara, M., Melloni, S., Spina, A., Quaranta, F. 2011. Linee e varietà di frumento duro per la resistenza alla fusariosi della spiga (Durum wheat lines and varieties for Fusarium Head Blight resistance). Proc. 8th AISTEC Congress. Catania, Italy. pp. 168-172. (in Italian)

Bernhoft, A., Clasen, P.-E., Kristoffersen, A.B., Torp, M. 2010. Less Fusarium infestation and mycotoxin contamination in organic than in conventional cereals. Food Additives and Contaminants: Part A, 27:842-852.

Błajet-Kosicka, A., Twarużek, M., Kosicki, R., Sibiorowska, E., Grajewski, J. 2014. Co-occurrence and evaluation of mycotoxins in organic and conventional rye grain and products. Food Control 38:61-66.

Blandino, M., Pascale, M., Plizzari, L., Scudellari, D., Reyneri, A. 2012. Integrated strategies for the control of Fusarium head blight and Deoxynivalenol contamination in winter wheat. Field Crops Research 133:139149.

Bottalico, A., Perrone, G. 2002. Toxigenic Fusarium species and mycotoxins associated with head blight in small-grain cereals in Europe. Eur. J. Plant Pathol. 108:611-624.

Brera, C. 2011. Linea guida sulla interpretazione dei regolamenti comunitari nella valutazione della conformità del Deossinivalenolo (DON) nel frumento e prodotti derivati (Guidelines on the interpretation of the Community regulations in assessing the conformity of Deoxynivalenol (DON) in wheat and wheat-derived products) Italmopa. http:/www.italmopa.com/archivio-storico/circolari/pubblicazione-volume-italmopabrera-don/1940 (Last accessed: December 23 ${ }^{\text {rd }}$ 2014). (in Italian)

Buerstmayr, H., Ban, T., Anderson, J.A. 2009. QTL mapping and marker-assisted selection for Fusarium head blight resistance in wheat. Plant Breeding 128:1-26.

Cendoya, E., Monge, M.P, Palacio,s S.A., Chiacchiera, S.M., Torres, A.M., Farnochi, M.C., Ramirez, M.L. 2010. Fumonisin occurrence in naturally contaminated wheat grain harvested in Argentina. Food Control 37:56-61.

Champeil, A., Fourbet, J.F., Doré, T., Rossignol, L. 2004. Influence of cropping system on Fusarium head blight and mycotoxin levels in winter wheat. Crop Protection 23:531-537.

Clear, R.M., Patrick, S.K., Gaba, D., Abramson, D., Smith, D.M. 2005. Prevalence of fungi and fusariotoxins on hard red spring and amber durum wheat seed from western Canada, 2000 to 2002. Can. J. Plant Pathol. 27:528-540.

Edwards S.G. 2009a. Fusarium mycotoxin content of UK organic and conventional wheat. Food Additives and Contaminants, Part A 26:496-503.

Edwards S.G. 2009b. Fusarium mycotoxin content of UK organic and conventional oat. Food Additives and Contaminants, Part A 26:1063-1069.

Edwards S.G. 2009c. Fusarium mycotoxin content of UK organic and conventional barley. Food Additives and Contaminants, Part A 26:1185-1190. 
European Commission 2006a. Commission Regulation (EC) No. 1881/2006 of 19 December 2006 setting maximum levels for certain contaminants in foodstuffs. Official J. of the European Union L364:5-24.

European Commission 2006b. Commission Regulation (EC) No. 401/2006 of 23 February 2006 laying down the methods of sampling and analysis for the official control of the levels of mycotoxins in foodstuffs. Official J. of the European Union L12/34:1-23.

European Commission 2013. Facts and figures on organic agriculture in the European Union. Available at: http://ec.europa.eu/agriculture/markets-and-prices/more-reports/pdf/organic-2013_en.pdf (last accessed: November, 04 $4^{\text {th }}$ 2014)

Fagnano, M., Fiorentino, N., D’Egidio, M.G., Quaranta, F., Ritieni, A., Ferracane, R., Raimondi, G. 2012. Durum wheat in conventional and organic farming:_yield amount and pasta quality in Southern Italy. The Scientific World Journal Volume 2012 (2012), Article number 973058, 9 pages. Available at http://www. hindawi.com/journals/tswj/2012/973058/ (Last accessed: May, 23 ${ }^{\text {rd }} 2015$ )

Fedak, G., Cao, W., Xue, W., Savard, M., Clarke, J., Somers, D.J. 2007. Enhancement of Fusarium Head Blight resistance in bread wheat and durum by means of wide crosses. In: Buck, H.T., Nisi, J.E., Salomón, N. (eds), Wheat Production in Stressed Environments. pp. 91-95.

Hooker, D.C., Schaafsma, A.W., Tamburic-Ilincic, L. 2002. Using weather variables pre- and post-heading to predict Deoxynivalenol content in winter wheat. Plant Disease 86:611-619.

Lori, G.A., Sisterna, M.N., Haidukowski, M., Rizzo, I. 2003. Fusarium graminearum and Deoxynivalenol contamination in the durum wheat area of Argentina. Microbiol. Res. 158:29-35.

Malmauret, L., Parent-Massin, D., Hardy, J.L., Verger, P. 2002. Contaminants in organic and conventional foodstuffs in France. Food Additives and Contaminants, Part A 19:524-532.

Mesterházy, A. 2002. Role of Deoxynivalenol in aggressiveness of Fusarium graminearum and F. culmorum and in resistance to Fusarium head blight. European J. Plant Pathol. 108:675-684.

Quaranta, F., Amoriello, T., Aureli, G., Belocchi, A., D’Egidio, M.G., Fornara, M., Melloni, S., Desiderio, E. 2010. Grain yield, quality and Deoxynivalenol (DON) contamination of durum wheat (Triticum durum desf.): Results of national networks in organic and conventional cropping systems. Italian J. Agron. 5:353366.

Rembiałkowska, E. 2007. Quality of plant products from organic agriculture. J. Sci. of Food and Agric. 87:2757-2752.

Schaafsma, A.W., Hooker, D.C., Tamburic-Ilincic, L., Miller, J.D. 2001. Agronomic considerations for reducing Deoxynivalenol content in wheat grain. Can. J. Plant Pathol. 23:279-285.

SINAB 2014. Bio in Cifre 2014. Available at: http://www.sinab.it/sites/default/files/share/bio $\% 20$ in $\% 20$ cifre\%202014_1.pdf (last accessed: November, 18 ${ }^{\text {th }}$ 2014)

Šliková, S., Šudyová, V., Gregová, E. 2008. Deoxynivalenol in wheat from the growing Areas of Slovakia. Cereal Res, Commun. 36:279-287.

Tamburic-Ilincic, L. 2012. Effect of 3B, 5A and 3A QTL for Fusarium head blight resistance on agronomic and quality performance of Canadian winter wheat. Plant Breeding 131:722-727.

Tittlemier, S.A., Roscoe, M., Trelka, R., Gaba, D., Chan, J.M., Patrick, S.K., Sulyok, M., Krska, R., McKendry, T., Gräfenhan, T. 2013. Fusarium damage in small cereal grains from Western Canada. 2. Occurrence of fusarium toxins and their source organisms in durum wheat harvested in 2010. J. Agric. Food Chem. 61:5438-5448.

Tóth, B., Kászonyi, G., Bartók, T., Varga, J., Mesterházy, A. 2008. Common resistance of wheat to members of the Fusarium graminearum species complex and F. culmorum. Plant Breeding 127:1-8. 


\section{Electronic Supplementary Material (ESM)}

Electronic Supplementary Material (ESM) associated with this article can be found at the website of CRC at http://www.akademiai.com/content/120427/

Electronic Supplementary Table S1. DON contamination in five growing areas and six cultivation years: mean, standard deviation (SD), range, median (Q2), 75th percentile (Q3), 95th percentile (P95), percentage and mean of positive samples. Values for areas and years and overall values are also reported

Electronic Supplementary Table $S 2 \cdot \chi^{2}$ values and significance levels from GLZ regression for DON

Electronic Supplementary Table S3. Occurrence and concentrations of DON for 13 durum wheat cultivars of different growth cycle

Electronic Supplementary Table S4. Mean temperature (T) and rainfall (R) in April, May and June in the study areas during the 6-year period 2007-2012

Electronic Supplementary Table S5. Range (min-max) of heading dates (expressed as days after April, $1^{\text {st }}$ ) in the different growing areas and cultivation years

Electronic Supplementary Table S6. Decadal values of mean temperature (T) and rainfall (R) in April and May in Northern Italy and Marches throughout the study period

Electronic Supplementary Figure S1. Geographical position of the study sites (1, Santa Giuletta; 2, San Pancrazio; 3, Jesi; 4, Pollenza; 5, Rispescia; 6, Tarquinia; 7, Introdacqua; 8, Campobasso; 9, Foggia; 10, Gravina)

Electronic Supplementary Figure S2. Distribution of DON contamination $(\mu \mathrm{g} / \mathrm{kg})$ on the whole dataset 